\title{
Papers
}

\section{Frequent nut consumption and risk of coronary heart disease in women: prospective cohort study}

Frank B Hu, Meir J Stampfer, JoAnn E Manson, Eric B Rimm, Graham A Colditz, Bernard A Rosner, Frank E Speizer, Charles H Hennekens, Walter C Willett

\begin{abstract}
Objective To examine the relation between nut consumption and risk of coronary heart disease in a cohort of women from the Nurses' Health Study. Design Prospective cohort study.

Setting Nurses' Health Study.

Subjects 86016 women from 34 to 59 years of age without previously diagnosed coronary heart disease, stroke, or cancer at baseline in 1980 .

Main outcome measures Major coronary heart disease including non-fatal myocardial infarction and fatal coronary heart disease.

Results 1255 major coronary disease events (861 cases of non-fatal myocardial infarction and 394 cases of fatal coronary heart disease) occurred during 14 years of follow up. After adjusting for age, smoking, and other known risk factors for coronary heart disease, women who ate more than five units of nuts (one unit equivalent to $1 \mathrm{oz}$ of nuts) a week (frequent consumption) had a significantly lower risk of total coronary heart disease (relative risk $0.65,95 \%$ confidence interval 0.47 to 0.89 , $\mathrm{P}$ for trend $=0.0009$ ) than women who never ate nuts or who ate less than one unit a month (rare consumption). The magnitude of risk reduction was similar for both fatal coronary heart disease $(0.61,0.35$ to 1.05 , $\mathrm{P}$ for trend $=0.007)$ and non-fatal myocardial infarction $(0.68,0.47$ to 1.00 , $\mathrm{P}$ for trend $=0.04)$. Further adjustment for intakes of dietary fats, fibre, vegetables, and fruits did not alter these results. The inverse association persisted in subgroups stratified by levels of smoking, use of alcohol, use of multivitamin and vitamin $\mathrm{E}$

supplements, body mass index, exercise, and intake of vegetables or fruits.

Conclusions Frequent nut consumption was associated with a reduced risk of both fatal coronary heart disease and non-fatal myocardial infarction. These data, and those from other epidemiological and clinical studies, support a role for nuts in reducing the risk of coronary heart disease.
\end{abstract}

\section{Introduction}

Nuts are an important part of the Mediterranean diet. The Mediterranean diet is thought to be healthy because mortality rates from coronary heart disease and cancer are low in traditional Mediterranean popu- lations. ${ }^{1}$ Recent epidemiological studies suggest that frequent nut consumption may be protective against coronary heart disease because of beneficial effects on blood lipids..$^{2-4}$ In clinical studies, diets supplemented with walnuts or almonds decreased serum concentrations of low density lipoprotein and cholesterol. ${ }^{5-7}$ Other potentially protective constituents include high amounts of protein, magnesium, vitamin $\mathrm{E}$, fibre, potassium, and $\alpha$ linolenic acid (primarily in walnuts). We examined the association between nut consumption and risk of coronary heart disease in a cohort of women in the Nurses' Health Study.

\section{Subjects and methods}

\section{Nurses' Health Study}

In 1976 the Nurses' Health Study was established, which includes detailed information on the medical history and lifestyle of 121700 registered female nurses aged 30 to 55 years. ${ }^{9}$ Every two years the women receive a follow up questionnaire so that information on potential risk factors for diseases can be updated, and newly diagnosed diseases such as coronary heart disease can be identified.

\section{Dietary questionnaires}

In 1980 a dietary questionnaire comprising 61 items was included as part of the follow up questionnaire to assess the women's intake of specific fats and other nutrients. In 1984 the dietary questionnaire was expanded to include 116 items. Similar questionnaires were used to update information on their diet in 1986 and 1990. The reproducibility and validity of the dietary questionnaires are described elsewhere. ${ }^{10}$

In the 1980 and 1984 dietary questionnaires we asked the participants how often, on average, during the previous year they had consumed nuts (one unit being equivalent to $1 \mathrm{oz}$ of nuts). We defined nine responses ranging from never to six or more times per day. Four categories for frequency of nut consumption included: almost never, 1-3 times per month to once per week, 2-4 times per week, and $\geqslant 5$ times per week. These categories were based on frequency distribution of the variables. In the 1986 and 1990 dietary questionnaires, the question was split into two items including peanuts and other nuts. Thus, consumption of total nuts in both 1986 and 1990 were these two
Editorial by Tunstall-Pedoe

Department of Nutrition, Harvard School of Public Health, Boston, MA 02115, USA Frank B Hu, research associate Meir J Stampfer, professor

Eric B Rimm, associate professor Walter C Willett, professor

Channing

Laboratory, Department of Medicine, Brigham and Women's

Hospital and

Harvard Medical

School, Boston, MA 02115, USA

Graham Colditz, professor

Bernard A Rosner, professor

Frank E Speizer,

professor

Division of

Preventive

Medicine,

Department of

Medicine, Brigham

and Women's

Hospital

JoAnn E Manson,

associate professor

Charles H

Hennekens,

professor

Correspondence to:

$\mathrm{Dr} \mathrm{Hu}$

Frank.Hu@channing. harvard.edu

BMJ 1998;317:1341-5 
items combined. The correlation coefficient between intake of nuts assessed by the 1980 questionnaire and by dietary records collected over four weeks was $0.66 .{ }^{11}$ Consumption of peanut butter (one tablespoon equivalent to $1 \mathrm{oz}$ of peanuts) was assessed in 1980, 1984, 1986, and 1990. The computation of intake of nutrients such as fats and fibre is described elsewhere. ${ }^{10}$

The 1980 dietary questionnaire was sent out up to four times. Overall, 98462 women returned the questionnaire. We excluded those questionnaires with 10 or more blank items or with implausibly high or low scores for total food intake or energy intake-that is, $<2.1$ MJ per day or $>14.6 \mathrm{MJ}$ per day. We also excluded those questionnaires from women with previously diagnosed cancer, angina, myocardial infarction, stroke, or other cardiovascular diseases because diagnosis of these conditions can lead to dietary changes. The final 1980 baseline population comprised 86016 women.

\section{Ascertainment of end points}

The primary end point was incident coronary heart disease, defined as non-fatal myocardial infarction or fatal coronary heart disease occurring after the return of the 1980 questionnaire but before 1 June 1994. The medical records of women who reported a non-fatal myocardial infarction were reviewed by physicians blinded to self reported risk factor status. Non-fatal myocardial infarction was confirmed in accordance with the criteria of the World Health Organisation plus either diagnostic electrocardiographic changes or elevated serum concentrations of cardiac enzymes. ${ }^{12}$ Myocardial infarctions that required hospital admission and for which confirmatory information was obtained, but for which no medical records were available, were designated as probable (17\%). We included all confirmed and probable cases in the analyses because results were the same after excluding probable cases. The follow up rate for non-fatal coronary disease events was 98\% (1 132 229/1 155 752) of the total potential person years of follow up.

Deaths were reported by families and postal officials and through the National Death Index. When all these sources were combined, follow up for the deaths was over $98 \%$ complete. $^{13}$ Fatal coronary heart disease was defined as fatal myocardial infarction if it was confirmed by hospital records or autopsy, or if coronary heart disease was listed as the cause of death on the death certificate and this was the underlying and most plausible cause, and evidence of previous coronary heart disease was available.

\section{Data analysis}

Person years for each participant were calculated from the date of return of the 1980 questionnaire to the date of the first coronary heart disease event, death, or 1 June 1994. Women were excluded from subsequent follow up if they had fatal coronary heart disease, confirmed non-fatal myocardial infarction, stroke, or cancer by the time of posting of the previous questionnaire.

We divided women into four categories according to their frequency of nut consumption: almost never, 1-3 times per month to once per week, 2-4 times per week, and $\geqslant 5$ times per week. We calculated incidence rates by dividing the number of events by person years of follow up in each category. The relative risk was computed as the rate in a specific category of nut consumption divided by that in the lowest category (almost never), with adjustment for age in five-year categories. In multivariate analyses, we simultaneously included intake of total energy, smoking, and other potential confounding variables. Tests of linear trend across increasing categories of nut consumption were conducted by treating the medians of consumption in categories as a continuous variable. In the primary analysis, incidence of coronary heart disease was related to nut consumption at baseline. In further analyses, the incidence of coronary heart disease was related to the cumulative average of nut consumption from all available questionnaires, using methods for repeated measures described previously. ${ }^{14}$ Potential confounding variables including age, cigarette smoking, body mass index, hormones for treating the menopause, alcohol, multivitamin, and vitamin $\mathrm{E}$ supplements were updated every two years. Aspirin use was assessed in 1980, 1982, 1984, and 1988. Vigorous exercise was assessed in 1980. Pooled logistic regression, equivalent to Cox regression with time dependent covariates, was used in multivariate analyses. ${ }^{15}$

\section{Results}

Nut consumption in the cohort decreased during the 1980 s. In 1980 , about $9 \%(7746 / 86016)$ of women reported eating 1 unit of nuts (equivalent to $1 \mathrm{oz}$ of nuts) 2-4 times per week, and 5\% (4423/86 016) of women reported eating nuts $\geqslant 5$ times per week. By 1990 the corresponding percentages decreased to $4.5 \%(3189 / 71247)$ and $3 \%$ (2269/71 247).

Women with frequent nut consumption in 1980 tended to smoke fewer cigarettes and to exercise and use multivitamin and vitamin E supplements more than women who rarely consumed nuts (table 1). Women who frequently consumed nuts were also leaner and more likely to use alcohol than women who rarely consumed nuts. Frequent nut consumption was associated with low intakes of trans fats and high intakes of polyunsaturated fat and fibre. Consumption of vegetables and fruits was similar in both women who ate nuts or those who never ate nuts. Women who consumed nuts ate less meat than those women who rarely ate nuts, although only $0.3 \%$ of women reported never eating meat.

During 1132229 person years of follow up from 1980 to 1994, we documented 861 cases of non-fatal myocardial infarction and 394 cases of fatal coronary heart disease. Frequency of nut consumption at baseline was inversely associated with total coronary heart disease in age adjusted analyses (table 2). The relative risk in women consuming nuts $\geqslant 5$ times per week compared with those who never ate nuts was 0.48 ( 0.35 to $0.65, \mathrm{P}$ for trend $=0.0001)$. After controlling for potential confounding variables the association was attenuated, reflecting a more favourable coronary risk profile in women who consumed nuts. The trend, however, remained significant (comparison with extreme categories was $0.65(0.47$ to 0.89 , $\mathrm{P}$ for trend $=0.0009)$ ). The corresponding relative risks were 0.61 ( 0.35 to 1.05 , $\mathrm{P}$ for trend $=0.007$ ) for fatal coronary heart disease and $0.68(0.47$ to $1.00, \mathrm{P}$ for trend $=0.04)$ for non-fatal myocardial infarction. After adjustment for potential dietary confounding variables such as intakes of saturated fat, polyunsaturated fat, trans fat, fibre, veg- 
Table 1 Relation of potential risk factors for coronary heart disease in women (age adjusted) to frequency of nut consumption ( $1 \mathrm{oz}$ serving) at baseline in 1980. Values are numbers (percentages) of women unless stated otherwise

Frequency of nut consumption

\begin{tabular}{|c|c|c|c|c|}
\hline \multirow[b]{2}{*}{ Variable } & \\
\hline & $\begin{array}{l}\text { Almost never } \\
(\mathrm{n}=29899)\end{array}$ & $\begin{array}{c}1-3 / \text { month to } \\
\text { once/week ( } n=43 \text { 948) }\end{array}$ & $\begin{array}{c}2-4 \text { times/week } \\
(n=7746)\end{array}$ & $\begin{array}{c}\geqslant 5 \text { times/week } \\
(n=4423)\end{array}$ \\
\hline Current smoker & $9568(32.0)$ & $11954(27.2)$ & $1960(25.3)$ & $1106(25.0)$ \\
\hline Hypertension & $5471(18.3)$ & $6504(14.8)$ & $1007(13.0)$ & $540(12.2)$ \\
\hline Diabetes & $747(2.5)$ & $791(1.8)$ & $139(1.8)$ & $102(2.3)$ \\
\hline Hypercholesterolaemia & $1614(5.4)$ & $2153(4.9)$ & $395(5.1)$ & $248(5.6)$ \\
\hline Parental myocardial infarction before age 60 & 4844 (16.2) & $6900(15.7)$ & $1208(15.6)$ & $655(14.8)$ \\
\hline Current hormone use postmenopausally & $4784(16.0)$ & 7735 (17.6) & $1503(19.4)$ & $805(18.2)$ \\
\hline Vigorous exercise ( $\geqslant$ once/week) & $12139(40.6)$ & $2017(45.9)$ & $4043(52.2)$ & $2384(53.9)$ \\
\hline Multivitamin use & $9089(30.4)$ & $14898(33.9)$ & $3191(41.2)$ & $2021(45.7)$ \\
\hline Vitamin E supplement use & $2870(9.6)$ & $5670(12.9)$ & $1464(18.9)$ & $1106(25.0)$ \\
\hline Current aspirin use ( $\geqslant$ once/week) & $13813(46.2)$ & $20875(47.5)$ & 3524 (45.5) & $1915(43.3)$ \\
\hline \multicolumn{5}{|l|}{ Mean } \\
\hline Age (years) & 46.0 & 45.8 & 46.8 & 47.5 \\
\hline Alcohol consumption (g/day) & 6.0 & 6.7 & 7.8 & 8.0 \\
\hline Body mass index $\left(\mathrm{kg} / \mathrm{m}^{2}\right)$ & 24.8 & 24.3 & 23.8 & 23.4 \\
\hline \multicolumn{5}{|l|}{ Diet } \\
\hline Saturated fat (\% energy) & 15.6 & 15.7 & 15.4 & 15.1 \\
\hline Polyunsaturated fat (\% energy) & 4.9 & 5.2 & 5.8 & 6.8 \\
\hline Trans fat (\% energy) & 2.3 & 2.3 & 2.1 & 1.8 \\
\hline Fibre (g/day) & 13.1 & 13.5 & 14.9 & 16.5 \\
\hline Vegetables (servings/day/4.2 MJ)* & 1.38 & 1.33 & 1.36 & 1.35 \\
\hline Fruit (servings/day/4.2 MJ)† & 1.39 & 1.36 & 1.38 & 1.39 \\
\hline Beef, pork, and lamb as main dish (servings/day/4.2 MJ) & 0.24 & 0.23 & 0.20 & 0.18 \\
\hline Chicken (servings/day/4.2 MJ) & 0.19 & 0.17 & 0.17 & 0.15 \\
\hline Fish (servings/day/4.2 MJ) & 0.13 & 0.11 & 0.12 & 0.11 \\
\hline Egg (servings/day/4.2 MJ) & 0.28 & 0.28 & 0.28 & 0.27 \\
\hline
\end{tabular}

${ }^{\star}$ Composite score of 11 vegetables.

†Composite score of six fruits.

etables, and fruits, the relative risk for total coronary heart disease from consuming nuts $\geqslant 5$ times per week was 0.66 (0.47 to 0.93) (table 2). Updated analyses using cumulative averages of nut consumption in 1980, 1984, 1986, and 1990 yielded similar results (data not shown). To examine further the independent association with nut consumption, we repeated the multivariate analyses within subgroups of potential confounding variables (table 3). An inverse association persisted in all subgroups, and we found no apparent modification of the relation between nut consumption and coronary heart disease risk by these variables. When the analysis was restricted to non-smokers and women who were teetotaller or who drank occasionally ( $\leqslant 1$ drink per week), the inverse association was particularly strong (relative risk of coronary heart

Table 2 Relative risks and 95\% confidence intervals of coronary heart disease in women according to frequency of nut consumption (1 oz serving)

\begin{tabular}{|c|c|c|c|c|c|}
\hline & \multicolumn{4}{|c|}{ Frequency of nut consumption } & \multirow[b]{2}{*}{$P$ for trend } \\
\hline & $\begin{array}{c}\text { Almost } \\
\text { never }\end{array}$ & $\begin{array}{l}\text { 1-3/month to } \\
\text { once/week }\end{array}$ & 2-4 times/week & $\geqslant 5$ times/week & \\
\hline \multicolumn{6}{|l|}{ Coronary heart disease } \\
\hline No of cases & 542 & 584 & 85 & 44 & - \\
\hline Person years & 391918 & 579805 & 102175 & 58330 & - \\
\hline Age adjusted relative risk & 1.0 & 0.74 (0.66 to 0.84$)$ & $0.56(0.44$ to 0.70$)$ & $0.48(0.35$ to 0.65$)$ & 0.0001 \\
\hline Multivariate relative risk ${ }^{*}$ & 1.0 & 0.91 (0.81 to 1.02$)$ & 0.77 (0.61 to 0.97$)$ & $0.65(0.47$ to 0.89$)$ & 0.0009 \\
\hline Additional adjustment for dietary variables $\dagger$ & 1.0 & 0.91 (0.81 to 1.03$)$ & 0.78 (0.61 to 0.99$)$ & 0.66 (0.47 to 0.93$)$ & 0.005 \\
\hline \multicolumn{6}{|l|}{ Fatal coronary heart disease } \\
\hline No of cases & 197 & 161 & 22 & 14 & - \\
\hline Age adjusted relative risk & 1.0 & $0.57(0.46$ to 0.70$)$ & $0.39(0.25$ to 0.61$)$ & $0.41(0.24$ to 0.70$)$ & 0.0001 \\
\hline Multivariate relative risk & 1.0 & 0.75 (0.61 to 0.93$)$ & 0.56 (0.36 to 0.89$)$ & $0.61(0.35$ to 1.05$)$ & 0.007 \\
\hline Additional adjustment for dietary variables & 1.0 & 0.76 (0.61 to 0.94$)$ & 0.60 (0.38 to 0.96$)$ & $0.60(0.33$ to 1.10$)$ & 0.004 \\
\hline \multicolumn{6}{|l|}{ Non-fatal myocardial infarction } \\
\hline No of cases & 345 & 423 & 63 & 30 & - \\
\hline Age adjusted relative risk & 1.0 & 0.85 (0.73 to 0.98$)$ & 0.66 (0.50 to 0.86$)$ & $0.52(0.36$ to 0.75$)$ & 0.0001 \\
\hline Multivariate relative risk & 1.0 & 1.00 (0.87 to 1.16$)$ & 0.87 (0.66 to 1.14$)$ & $0.68(0.47$ to 1.00$)$ & 0.04 \\
\hline Additional adjustment for dietary variables & 1.0 & 1.00 (0.87 to 1.16$)$ & 0.89 (0.66 to 1.18$)$ & 0.71 (0.47 to 1.07$)$ & 0.19 \\
\hline \multicolumn{6}{|c|}{$\begin{array}{l}\text { *Models include: age (5-year category); time period (7 periods); body mass index (five categories); cigarette smoking (never, past, and current smoking of } 1-14 \text {, } \\
15-24 \text {, and } \geqslant 25 \text { cigarettes per day); history of hypertension, diabetes, and hypercholesterolaemia; menopausal status (premenopausal, postmenopausal without } \\
\text { hormone replacement, postmenopausal with past hormone replacement, postmenopausal with current hormone replacement); parental history of myocardial } \\
\text { infarction before } 60 \text { years of age; use of multivitamins; use of vitamin E supplements; alcohol consumption (four categories); aspirin use (non-user, } 1-6 / \text { week, } \\
\geqslant 7 / \text { week, and dose unknown); vigorous exercise } \geqslant 1 / \text { week; and total energy intake. }\end{array}$} \\
\hline
\end{tabular}


Table 3 Multivariate relative risks ${ }^{\star}$ of coronary heart disease in women according to frequency of nut consumption ( $1 \mathrm{oz}$ serving) at baseline, stratified by risk factors

Frequency of nut consumption

\begin{tabular}{|c|c|c|c|c|c|}
\hline \multirow[b]{2}{*}{ Variable } & & \multirow[b]{2}{*}{$P$ for trenc } \\
\hline & $\begin{array}{c}\text { Almost } \\
\text { never }\end{array}$ & $\begin{array}{l}1-3 / \text { month to } \\
\text { once/week }\end{array}$ & $\begin{array}{c}2-4 \\
\text { times/week }\end{array}$ & $\geqslant 5$ times/week & \\
\hline \multicolumn{6}{|c|}{ Hypertension } \\
\hline Yes & 1.0 & 0.87 & 0.74 & $0.76(0.50$ to 1.14$)$ & 0.05 \\
\hline No & 1.0 & 0.97 & 0.81 & $0.55(0.34$ to 0.90$)$ & 0.01 \\
\hline \multicolumn{6}{|l|}{ Diabetes } \\
\hline Yes & 1.0 & 0.81 & 0.77 & $0.53(0.24$ to 1.41$)$ & 0.07 \\
\hline No & 1.0 & 0.95 & 0.77 & $0.68(0.48$ to 0.96$)$ & 0.006 \\
\hline \multicolumn{6}{|c|}{ Hypercholesterolaemia } \\
\hline Yes & 1.0 & 0.84 & 0.62 & 0.61 (0.57 to 1.00$)$ & 0.007 \\
\hline No & 1.0 & 0.96 & 0.87 & $0.68(0.45$ to 1.02$)$ & 0.05 \\
\hline \multicolumn{6}{|c|}{ Multivitamin use } \\
\hline Yes & 1.0 & 0.96 & 0.86 & $0.52(0.30$ to 0.91$)$ & 0.03 \\
\hline No & 1.0 & 0.89 & 0.71 & $0.72(0.50$ to 1.06$)$ & 0.01 \\
\hline \multicolumn{6}{|c|}{ Vitamin E supplement use } \\
\hline Yes & 1.0 & 1.05 & 0.88 & $0.52(0.24$ to 1.12$)$ & 0.08 \\
\hline No & 1.0 & 0.89 & 0.75 & 0.68 (0.48 to 0.96$)$ & 0.004 \\
\hline \multicolumn{6}{|c|}{ Parental history of myocardial infarction before age $\mathbf{6 0}$} \\
\hline Yes & 1.0 & 0.84 & 0.75 & $0.60(0.31$ to 1.15$)$ & 0.07 \\
\hline No & 1.0 & 0.94 & 0.77 & $0.67(0.47$ to 0.96$)$ & 0.007 \\
\hline \multicolumn{6}{|c|}{ Current smoking } \\
\hline Yes & 1.0 & 0.85 & 0.84 & 0.75 (0.47 to 1.19$)$ & 0.15 \\
\hline No & 1.0 & 0.93 & 0.69 & 0.58 (0.38 to 0.88$)$ & 0.001 \\
\hline \multicolumn{6}{|c|}{ Current alcohol use } \\
\hline Yes & 1.0 & 0.96 & 0.71 & $0.71(0.48$ to 1.06$)$ & 0.01 \\
\hline No & 1.0 & 0.85 & 0.86 & $0.57(0.34$ to 0.95$)$ & 0.03 \\
\hline \multicolumn{6}{|c|}{ Body mass index $\left(\mathrm{kg} / \mathrm{m}^{2}\right)$} \\
\hline$<25$ & 1.0 & 0.90 & 0.69 & $0.58(0.38$ to 0.89$)$ & 0.002 \\
\hline$\geqslant 25$ & 1.0 & 0.92 & 0.87 & 0.75 (0.47 to 1.19$)$ & 0.18 \\
\hline \multicolumn{6}{|c|}{ Vigorous exercise $\geqslant 1 /$ week } \\
\hline Yes & 1.0 & 0.89 & 0.67 & 0.63 (0.37 to 1.08$)$ & 0.02 \\
\hline No & 1.0 & 0.92 & 0.80 & $0.66(0.45$ to 0.98$)$ & 0.02 \\
\hline
\end{tabular}

Dietary intake

Vegetables (servings/day)

\begin{tabular}{|c|c|c|c|c|c|}
\hline$<2$ & 1.0 & 0.93 & 0.69 & 0.71 (0.47 to 1.08$)$ & 0.01 \\
\hline$\geqslant 2$ & 1.0 & 0.88 & 0.85 & 0.58 (0.36 to 0.93$)$ & 0.03 \\
\hline \multicolumn{6}{|c|}{ Fruit (servings/day): } \\
\hline$<2$ & 1.0 & 0.88 & 0.75 & $0.72(0.47$ to 1.12$)$ & 0.04 \\
\hline$\geqslant 2$ & 1.0 & 0.95 & 0.80 & 0.60 (0.38 to 0.94$)$ & 0.01 \\
\hline \multicolumn{6}{|c|}{ Fibre (g/day): } \\
\hline$<10$ & 1.0 & 0.73 & 0.60 & 0.77 (0.28 to 2.09$)$ & 0.06 \\
\hline$\geqslant 10$ & 1.0 & 0.98 & 0.81 & 0.67 (0.48 to 0.93$)$ & 0.005 \\
\hline \multicolumn{6}{|c|}{ Saturated fat ${ }^{\star *}$ : } \\
\hline Low & 1.0 & 1.05 & 0.78 & 0.65 (0.40 to 1.00$)$ & 0.02 \\
\hline High & 1.0 & 0.81 & 0.77 & 0.70 (0.45 to 1.08$)$ & 0.04 \\
\hline \multicolumn{6}{|c|}{ Polyunsaturated fat: } \\
\hline Low & 1.0 & 0.97 & 0.81 & 0.77 (0.44 to 1.33$)$ & 0.19 \\
\hline High & 1.0 & 0.91 & 0.76 & 0.68 (0.44 to 1.06$)$ & 0.04 \\
\hline \multicolumn{6}{|c|}{ Trans fat: } \\
\hline Low & 1.0 & 0.92 & 0.89 & 0.69 (0.47 to 1.02$)$ & 0.08 \\
\hline High & 1.0 & 0.91 & 0.63 & 0.62 (0.35 to 1.08$)$ & 0.006 \\
\hline
\end{tabular}

*Adjusting for age (5-year category); time period (7 periods); body mass index (five categories); cigarette smoking (never, past, and current smoking of $1-14,15-24$, and $\geqslant 25$ cigarettes per day); history of hypertension, diabetes, and hypercholesterolaemia; menopausal status (premenopausal, postmenopausal without hormon replacement, postmenopausal with past hormone replacement, postmenopausal with current hormone replacement); parental history of myocardial infarction before 60 years of age; use of multivitamins; use of vitamin E supplements; alcohol consumption (four categories); aspirin use (non-user, 1-6/week, $\geqslant 7 /$ week, and dose unknown); vigorous exercise $\geqslant 1 /$ week; and total energy intake. The variable used for stratification was not included in the model.

**Median values were used as cut off point; same for polyunsaturated fat and trans fat.

disease for consumption of nuts $\geqslant 5$ times per week was $0.48(0.27$ to 0.84 , $\mathrm{P}$ for trend $=0.008)$ ).

In analyses of peanuts and other nuts (assessed in 1986) separately, we combined the two highest categories because of the small number of cases (table 4). After adjusting for age, consumption of peanuts and other nuts were both inversely associated with risk of coronary heart disease.
Consumption of peanut butter was only weakly associated with risk of coronary heart disease (multivariate relative risk comparing women consuming peanut butter $\geqslant 5$ times per week with those who rarely consumed peanut butter was 0.92 (0.74 to 1.15 ), $P$ for trend $=0.94)$. The relative risk was slightly stronger for fatal coronary heart disease $(0.76,0.50$ to 1.15 , $\mathrm{P}$ for trend $=0.09$ ).

\section{Discussion}

In this large prospective study, frequent nut consumption in women was associated with a significantly reduced risk of coronary heart disease. Women who consumed nuts $\geqslant 5$ times per week had about a $35 \%$ lower risk of coronary heart disease than those women who rarely ate nuts.

We considered the possibility that confounding may explain the observed inverse association because women who frequently consumed nuts had a healthier lifestyle and diet than those who rarely ate nuts (table 1). Our detailed analyses, however, took the differences in these factors into account. As expected such adjustments attenuated the associations, but a clear and statistically significant risk reduction persisted. Women who ate nuts tended to eat less meat than those who rarely ate nuts, but the differences were modest, and very few women were vegetarians. Adjustment for intakes of vegetables, fruits, red meat, and fat did not appreciably alter our results. In addition the inverse association was present in all subgroup analyses further suggesting an apparent independent protective effect. Although we cannot rule out the possibility of residual confounding it is unlikely that it can fully explain the observed strong inverse association.

Another potential concern is inaccurate assessment of nut consumption. However, nut consumption was reported on dietary questionnaires with reasonable accuracy. ${ }^{11}$ Moreover, misclassification of exposure would most likely bias the relative risks toward null. We assessed nut consumption repeatedly during follow up so that our updated analyses took into account dietary changes.

Table 4 Relative risks of coronary heart disease in women according to frequency of consumption of peanuts and other nuts (1 oz serving) reported in 1986

\begin{tabular}{lcccc} 
& \multicolumn{3}{c}{ Frequency of nut consumption } & P for \\
\cline { 2 - 5 } Type of nut & $\begin{array}{c}\text { Almost } \\
\text { never }\end{array}$ & $\begin{array}{c}\mathbf{1 - 3 / m o n t h ~ t o ~} \\
\text { once/week }\end{array}$ & $\geqslant 2-4$ times/week & $\begin{array}{c}\text { trend } \\
\text { Peanut }\end{array}$ \\
\hline No of cases & 330 & 242 & 36 & - \\
\hline Age adjusted & 1.0 & $0.87(0.74$ to 1.03$)$ & $0.57(0.41$ to 0.81$)$ & 0.001 \\
\hline Multivariate* & 1.0 & $0.96(0.81$ to 1.13$)$ & $0.66(0.46$ to 0.94$)$ & 0.06 \\
\hline Other & & & & \\
\hline No of cases & 360 & 228 & 20 & - \\
\hline Age adjusted & 1.0 & $1.00(0.85$ to 1.18$)$ & $0.64(0.41$ to 1.00$)$ & 0.23 \\
\hline Multivariate & 1.0 & $1.14(0.96$ to 1.35$)$ & $0.79(0.50$ to 1.25$)$ & 0.62 \\
\hline
\end{tabular}

${ }^{*}$ Adjusting for age (5-year category); time period (7 periods); body mass index (five categories); cigarette smoking (never, past, and current smoking of 1-14, $15-24$, and $\geqslant 25$ cigarettes per day); history of hypertension, diabetes, and hypercholesterolaemia; menopausal status (premenopausal, postmenopausal without hormone replacement, postmenopausal with past hormone

replacement, postmenopausal with current hormone replacement); parental history of myocardial infarction before 60 years of age; use of multivitamins; use of vitamin E supplements; alcohol consumption (four categories); aspirin use (non-user, 1-6/week, $\geqslant 7 /$ week, and dose unknown); vigorous exercise $\geqslant 1 /$ week; and total energy intake. 
Our results are consistent with other epidemiological studies. ${ }^{23}$ In the Adventist Health Study, subjects who consumed nuts $\geqslant 5$ times per week had a $50 \%$ reduced risk of coronary heart disease than those who never consumed nuts. ${ }^{2}$ In the Iowa Women's Health Study, the relative risk of death from a coronary event in women who consumed nuts 2-4 times per week with those who almost never consumed nuts was $0.43 .^{3}$

It is biologically plausible that nut consumption can reduce the risk of coronary heart disease. Although nuts are high in fat, the fat is mostly unsaturated, ${ }^{8}$ which has beneficial effects on blood lipids. ${ }^{4}$ Sabate randomised 18 men with normal serum cholesterol concentrations to either a control diet or a diet enriched with walnuts and then switched the diets after 4 weeks. ${ }^{5}$ Both diets conformed to those of the national cholesterol education programme. Walnuts provided $20 \%$ of calories in the walnut diet, replacing animal and visible fat. The walnut diet lowered the ratio of serum concentrations of low density lipoprotein: high density lipoprotein by $12 \%$. Diets supplemented with almonds have also shown a cholesterol lowering effect. ${ }^{6} 7$

As well as having potential beneficial effects on blood lipids, nuts may protect against coronary heart disease through other mechanisms. ${ }^{16}{ }^{17}$ Most nuts are rich in arginine, the precursor of nitric oxide, an endothelium derived relaxing factor. ${ }^{18}$ Nitric oxide is a potent vasodilator and can inhibit platelet adhesion and aggregation. In addition, walnuts are high in $\alpha$ linolenic acid (about $10 \%$ of weight). High intakes of $\alpha$ linolenic acid have been associated with reduced risk of coronary heart disease in several prospective studies, possibly due to the antithrombotic and antiarrhythmic effects of $\alpha$ linolenic acid. ${ }^{1920}$ Other postulated explanations for benefits of nuts include their high content of magnesium, copper, folic acid, protein, potassium, fibre, and vitamin E. ${ }^{8} 17$

Frequent consumption of peanuts was associated with a low risk of coronary heart disease. Although one study showed that peanut oil was atherogenic when fed to rats and rabbits, ${ }^{21}$ in another study it was antiatherogenic when fed to cynomolgus monkeys; the blend of fats approximated the fatty acid composition of the average diet in the United States. ${ }^{22}$ In addition, a low fat diet supplemented with peanuts appreciably improved serum lipoprotein profiles when compared with a regular low fat diet in postmenopausal women with raised serum cholesterol concentrations. ${ }^{23}$ As different types of nuts comprise similar nutrients, reflected by their similar lipid profile, ${ }^{8}$ we do not expect the inverse association to differ between peanuts and other nuts. Peanut butter was only weakly associated with a risk of coronary heart disease, but this may be due to the addition of hydrogenated fat to major American brands. ${ }^{24}$

In conclusion, frequent nut consumption was associated with a reduced risk of both fatal coronary heart disease and non-fatal myocardial infarction in our large prospective study. These data, and those of other epidemiological and clinical studies, support a role for nuts in reducing coronary heart disease risk.

We thank the participants in the Nurses' Health Study, and Al Wing, Mark Shneyder, Gary Chase, Karen Corsano, Lisa Dunn, Barbara Egan, Lori Ward, and Jill Arnold.

Contributors: FBH conceived and designed the study, performed the statistical analyses, and wrote the manuscript. MJS and WCW conceived and designed the study, interpreted
- Nuts are high in fat, but most of the fatty acids are unsaturated

- This study suggests that frequent consumption of nuts, including peanuts, may reduce the risk of coronary heart disease

- This protective effect may be partly mediated through serum lipids because unsaturated fats have benefical effects on serum lipids. Other potentially protective constituents include vegetable protein, magnesium, vitamin E, fibre, and potassium

- Nuts can be included as part of a healthy diet

the statistical analyses, and edited the final manuscript; WCW will act as guarantor for the paper. JEM, EBR, GAC, BAR, FES, and $\mathrm{CHH}$ interpreted the results and edited the final manuscript.

Funding: This study was supported by research grants HL24074, HL34594, CA40356, and DK46200 and the nutrition training grant T32DK07703 from the United States National Institute of Health.

Competing interests: None declared.

1 Willett WC. Diet and health: What should we eat? Science 1994;264:532-7.

2 Fraser GE, Sabate J, Beeson WL, Strahan TM. A possible protective effect of nut consumption on risk of coronary heart disease. The Adventist Health Study. Arch Intern Med 1992;152:1416-24.

3 Prineas RJ, Kushi LH, Folsom AR, Bostick RM, Wu Y. Walnuts and serum Prineas RJ, Kushi LH, Folsom AR, Bostipids. N Engl J Med 1993;328:603-7.
liping

4 Grundy SM, Denke MA. Dietary influences on serum lipids and lipoproteins. J Lipid Res 1990;31:1149-72.

5 Sabate J, Fraser GE, Burke K, Knutsen S, Bennett H, Lindsted KD. Effects of walnuts on serum lipid levels and blood pressure in normal men. $N$ Engl J Med 1993;328:603-7.

6 Abbey M, Noakes M, Belling GB, Nestel P. Partial replacement of saturated fatty acids with almonds or walnuts lowers total plasma cholesterol and low-density-lipoprotein cholesterol. Am J Clin Nutr 1994;59:995-9.

7 Spiller GA, Jenkins D, Gragen LN, Gates JE, Bosello O, Berra K, et al. Effect of a diet high in monounsaturated fat from almonds on plasma cholesterol and lipoproteins. J Am Coll Nutr 1992;11:126-30.

8 Dreher ML, Maher CV. The traditional and emerging role of nuts in healthful diets. Nutr Rev 1996;54:241-5.

9 Colditz GA, Manson JE, Hankinson SE. The Nurses' Health Study: 20-year contribution to the understandiong of health among women. $J$ Wom Health 1997;6:49-62.

10 Willett WC. Nutritional epidemiology. New York: Oxford University Press, 1990.

11 Salvini S, Hunter DJ, Sampson L, Stampfer MJ, Colditz GA, Rosner B, et al. Food-based validation of a dietary questionnaire: the effects of week-to-week variation in food consumption. Int J Epidemiol 1989;18: 858-67.

12 Rose GA, Blackburn H. Cardiovascular survey methods. WHO Monograph Series No 58. Geneva: World Health Organisation, 1982.

13 Stampfer MJ, Willett WC, Speizer FE, Dysert DC, Lipnick R, Rosner B, et al. Test of the National Death Index. Am J Epidemiol 1984;119:837-9.

14 Hu FB, Stampfer MJ, Manson JE, Rimm E, Colditz GA, Rosner BA, et al. Dietary fat intake and the risk of coronary heart disease in women. $N$ Eng J Med 1997;337:1491-9.

15 D'Agostino RB, Lee M-L, Belanger AJ, Cupples LA, Anderson K, Kannel WB. Relation of pooled logistic regression to time dependent cox regression analysis: The Framingham Heart Study. Stat Med 1990;9 1501-15.

16 Sabate J. Does nut consumption protest against ischemic heart disease. Eur J Clin Nutr 1993;47:71-5S.

17 Fraser GE. Diet and coronary heart disease: beyond dietary fats and lowdensity-lipoprotein cholesterol. Am J Clin Nutr 1994;59:1117-235.

18 Cooke JP, Tsao P, Singer A, Wang B-Y, Kosek J, Drexler H. Anti-atherogenic effect of nuts: Is the answer NO? Arch Intern Med 1993;153:898-9. 19 Dolecek TA. Epidemiological evidence of relationships between dietary
polyunsaturated fatty acids and mortality in the multiple risk factor intervention trial. Proc Soc Exp Biol Med 1992;200:177-182.

20 Ascherio A, Rimm EB, Giovannucci EL, Spiegelman D, Stampfer MJ, Willett WC. Dietary fat and risk of coronary heart disease in men: cohort follow up study in the United States. BMJ 1996;313:84-90.

21 Kritchevsky D. Dietary fat and experimental atherosclerosis. Int J Tiss Reac 1991;XIII:59-65.

22 Alderson LM, Hays KC, Nicolosi RJ. Peanut oil reduces diet-induced atherosclerosis in cynomolgus monkeys. Arteriosclerosis 1986;6:465-74.

23 O'Byrne DJ, Knauft DA, Shireman RB. Low fat-monounsaturated rich diets containing high-oleic peanuts improve serum lipoprotein profiles. Lipids 1997;32:687-95.
Lipits

24 United States Department of Agriculture. Composition of foods-raw, processed, and prepared, 1963-1988. Agricultural Handbook No 8 Series. Washington, DC: Department of Agriculture, Government Printing Office, 1989 .

(Accepted 28 July 1998) 